\title{
Hydrogen sulfide attenuates spatial memory impairment and hippocampal neuroinflammation in beta-amyloid rat model of Alzheimer's disease
}

\author{
Aiguo Xuan ${ }^{1 *}$, Dahong Long ${ }^{1}$, Jianhua Li ${ }^{2}$, Weidong $\mathrm{Ji}^{3}$, Meng Zhang ${ }^{4}$, Lepeng Hong ${ }^{1}$ and Jihong Liu ${ }^{4}$
}

\begin{abstract}
Background: Endogenously produced hydrogen sulfide $\left(\mathrm{H}_{2} \mathrm{~S}\right)$ may have multiple functions in brain. An increasing number of studies have demonstrated its anti-inflammatory effects. In the present study, we investigated the effect of sodium hydrosulfide ( $\mathrm{NaHS}, \mathrm{H}_{2} \mathrm{~S}$ donor) on cognitive impairment and neuroinflammatory changes induced by injections of Amyloid- $\beta_{1-40}\left(A \beta_{1-40}\right)$, and explored possible mechanisms of action.

Methods: We injected $A \beta_{1-40}$ into the hippocampus of rats to mimic rat model of Alzheimer's disease (AD). Morris water maze was used to detect the cognitive function. Terminal deoxynucleotidyl transferase-mediated dUTP nick end labeling (TUNEL) assay was performed to detect neuronal apoptosis. Immunohistochemistry analyzed the response of glia. The expression of interleukin (IL)-1 $\beta$ and tumor necrosis factor (TNF)-a was measured by enzyme-linked immunosorbent assay (ELISA) and quantitative real-time polymerase chain reaction (qRT-PCR). The expression of $A \beta_{1-40,}$, phospho-p38 mitogen-activated protein kinase (MAPK), phospho-p65 Nuclear factor (NF)-KB, and phospho-c-Jun N-terminal Kinase (JNK) was analyzed by western blot.
\end{abstract}

Results: We demonstrated that pretreatment with NaHS ameliorated learning and memory deficits in an $A \beta_{1-40}$ rat model of AD. NaHS treatment suppressed $A \beta_{1-40}$-induced apoptosis in the CA1 subfield of the hippocampus. Moreover, the over-expression in IL-1 $\beta$ and TNF- $\alpha$ as well as the extensive astrogliosis and microgliosis in the hippocampus induced by $A \beta_{1-40}$ were significantly reduced following administration of NaHS. Concomitantly, treatment with NaHS alleviated the levels of p38 MAPK and p65 NF-kB phosphorylation but not JNK phosphorylation that occurred in the $A \beta_{1-40}$-injected hippocampus.

Conclusions: These results indicate that NaHS could significantly ameliorate $A \beta_{1-40}$-induced spatial learning and memory impairment, apoptosis, and neuroinflammation at least in part via the inhibition of p38 MAPK and p65 NF-kB activity, suggesting that administration of NaHS could provide a therapeutic approach for AD.

Keywords: Alzheimer's disease, Amyloid- $\beta$, Neuroinflammation, Hydrogen sulfide, p38 mitogen-activated protein kinase, p65 nuclear factor-kB

\section{Background}

Alzheimer's disease (AD) is a devastating and progressive neurodegenerative disorder characterized by extracellular deposition of Amyloid- $\beta$ (A $\beta$ ) protein and intraneuronal neurofibrillary tangles (NFTs). Microglia have been implicated in the progressive nature of numerous neurodegenerative or neuroinflammatory diseases such as $\mathrm{AD}$ [1]. The premise of deleterious

\footnotetext{
*Correspondence: xag2005@sohu.com

'Department of Anatomy, Guangzhou Medical University, Guangzhou, China Full list of author information is available at the end of the article
}

microglial activation in $\mathrm{AD}$ has been supported by analysis of postmortem brains of patients with $\mathrm{AD}$ [2], where microglial over-activation occurred before neuropil damage, suggesting that it plays a causal role in the development of $\mathrm{AD}$. The core of the senile plaque is the deposition of $A \beta$ and the activated microglia and astroglia are around the senile plaque. In these glias, numerous inflammation factors including interleukin-1 $\beta$ (IL-1 $\beta$ ), interleukin-6 (IL-6), tumor necrosis factor- $\alpha$ (TNF- $\alpha$ ) and inducible nitric oxide synthase (iNOS), and cyclooxygenase-2 (COX-2), and so on, are overexpressed 
$[3,4]$. Accumulating evidence indicates that neuroinflammatory processes may contribute to the pathophysiology of AD. However, traditional anti-inflammatory therapies such as non-steroidal anti-inflammatory drugs (NSAIDs) have produced mixed and conflicting results [5], highlighting the need for new and more specific antiinflammatory targets.

Hydrogen sulfide $\left(\mathrm{H}_{2} \mathrm{~S}\right)$ is best known as a poisonous gas with an extremely unpleasant odor. It is endogenously produced in the brain from cysteine by cystathionine $\beta$-synthase (CBS) and cystathione $\gamma$-lyase (CGL) [6]. $\mathrm{CBS}$ is the main $\mathrm{H}_{2} \mathrm{~S}$ producing enzyme in brain. A recent study showed that 3-mercaptopyruvate sulfurtransferase (3MST) in combination with cysteine aminotransferase (CAT) also produces $\mathrm{H}_{2} \mathrm{~S}$ from cysteine. In addition, 3MST is localized to neurons, and the levels of bound sulfane sulfur, the precursor of $\mathrm{H}_{2} \mathrm{~S}$, are greatly increased in the cells expressing 3MST and CAT but not increased in cells expressing functionally defective mutant enzymes [7]. Numerous studies showed that $\mathrm{H}_{2} \mathrm{~S}$ has anti-oxidant, anti-apoptotic effects in neuron and glial cells $[8,9] . \mathrm{H}_{2} \mathrm{~S}$ induces alterations in $\mathrm{Ca}^{2+}$ in astrocytes and microglia $[10,11]$, suggesting it may have anti-inflammatory properties. $\mathrm{H}_{2} \mathrm{~S}$ produces an antiinflammatory effect in lipopolysaccharide (LPS)-induced inflammation in both primary cultured microglia and immortalized murine BV-2 microglial cells [12]. The levels of S-adenosylmethionine (SAM), an activator of $\mathrm{CBS}$, are lower in AD brains than that in the brains of normal individuals [13]. Another study showed that $\mathrm{H}_{2} \mathrm{~S}$ is an endogenous anti-inflammatory and neuroprotective agent, and $\mathrm{H}_{2} \mathrm{~S}$ releasing drugs may have therapeutic potential in neurodegenerative disorders of aging such as $\mathrm{AD}$ and Parkinson's disease (PD) [14].

The above-mentioned roles of $\mathrm{H}_{2} \mathrm{~S}$ raise the possibility that $\mathrm{H}_{2} \mathrm{~S}$ may be associated with the pathology of AD. However, so far, a possible role for $\mathrm{H}_{2} \mathrm{~S}$ as an antiinflammatory agent in rat model of $\mathrm{AD}$ has not been extensively evaluated. The focus of the present study was to elucidate the effect of NaHS on cognitive impairment and neuroinflammatory changes in rat model of $\mathrm{AD}$ as well as possible mechanisms of action.

\section{Methods}

\section{Surgery and drug administration}

Healthy male Wistar rats (220 to $250 \mathrm{~g}$ ) were randomly divided into four groups ( $n=56$ for each group): sham (control) group, sham $+\mathrm{NaHS}$ group, $A \beta_{1-40}$ group, and $A \beta_{1-40}+\mathrm{NaHS}$ group. Rats in the $A \beta_{1-40}+\mathrm{NaHS}$ group were administered with NaHS (Sigma, USA) by intraperitoneal injection (i.p.) at a dose of $5 \mathrm{mg} / \mathrm{kg}$ once daily, 3 days before surgery and thereafter continuously for 9 days $[15,16]$. Three days after treatment with NaHS, anesthesia was induced by chloral hydrate $(35 \mathrm{mg} / 100 \mathrm{~g}$ weight, i.p.). $A \beta_{1-40}(10 \mathrm{nmol}$ in $10 \mu \mathrm{L}$ of sterile PBS) was incubated at $37^{\circ} \mathrm{C}$ for 1 week to induce the aggregation of $A \beta_{1-40}$ [17]. The aggregated $A \beta_{1-40}$ and vehicle was injected slowly over $10 \mathrm{~min}$ into the right dentate gyrus (DG) of rats at the following coordinates: anterior/ posterior $-3.3 \mathrm{~mm}$, media/lateral $2.0 \mathrm{~mm}$, and dorsal/ ventral $-3.3 \mathrm{~mm}$ ventral to the skull surface. The rectal temperature was maintained at $36^{\circ} \mathrm{C}$ to $37^{\circ} \mathrm{C}$ for all animals throughout the experiment. All animal experiments were performed according to protocols approved by the local animal care committee.

\section{Morris water maze}

The Morris water maze task was evaluated as previously described [18] with slight modification. Trials were performed during days 8 to 11 after the injection of $A \beta_{1-40}$. The task for all of the animals in each trial consisted of finding a hidden clear plastic platform $(10 \mathrm{~cm}$ diameter) that was placed $50 \mathrm{~cm}$ away from the wall of the water maze $(150 \mathrm{~cm}$ in diameter, $60 \mathrm{~cm}$ in depth) and $1 \mathrm{~cm}$ below the water. The platform remained in the same position for all trials and sessions. The starting quadrant was randomized every day, with all animals using the same order. The animals were faced towards the pool wall before being released. The time required to reach the hidden platform and the swimming speed were recorded. The animals were allowed to rest $30 \mathrm{~s}$ on the platform between trials. If an animal failed to reach the platform in $120 \mathrm{~s}$, it was manually guided to the platform. Each animal underwent two sessions (each contains four trials: NE; NW; SE; SW) per day for 4 consecutive days. Before surgery, animals were screened (without platform in the pool) for any rats that could not swim. Seven days after the injection of $A \beta_{1-40}$, animals were examined as above.

\section{Immunohistochemistry and TUNEL staining}

Immunohistochemistry was performed on the eighth day after $A \beta_{1-40}$ injection. After being microwaved for 5 min and washed three times in PBS ( $\mathrm{pH} 7.4$ ), sections were successively incubated with $0.3 \% \mathrm{H}_{2} \mathrm{O}_{2}$ in methanol for $10 \mathrm{~min}, 10 \%$ normal goat serum in PBS for $20 \mathrm{~min}$, and primary antibody (anti-GFAP, anti-OX42, Millipore, USA) dissolved in $2 \%$ normal goat serum, $0.3 \%$ Triton $\mathrm{X}-100,0.05 \% \mathrm{NaN}_{3}$ in $\mathrm{PBS}$ at $4^{\circ} \mathrm{C}$ overnight, and then $37^{\circ} \mathrm{C}$ for $30 \mathrm{~min}$. After rinsing three times in PBS, the sections were incubated with biotinylated anti-mouse or anti-rabbit secondary antibodies (Boster, China) in PBS for $30 \mathrm{~min}$ at $37^{\circ} \mathrm{C}$, then incubated with avidin-biotinperoxidase solution (SABC kit, Boster, China) and colorized with a DAB kit (Boster, China).

To detect cells undergoing apoptosis, TUNEL technique was performed according to the manufacturer's protocol supplied within the in situ Cell Death Detection 
Kit. The sections were immersed in $3 \% \mathrm{H}_{2} \mathrm{O}_{2}$ for inactivation of endogenous hydrogen peroxidase activity. After rinsing with PBS, the sections were incubated with proteinase $\mathrm{K}$ solution at $37^{\circ} \mathrm{C}$ for $20 \mathrm{~min}$ to enhance the permeability. Then they were incubated for $60 \mathrm{~min}$ at $37^{\circ} \mathrm{C}$ with TUNEL reaction mixture and again incubated for $30 \mathrm{~min}$ at $37^{\circ} \mathrm{C}$ with converterPOD. The sections were rinsed in PBS, incubated for 10 min with $\mathrm{DAB}$ substrate solution and rinsed again with PBS. Counter staining was done with $0.5 \%$ methyl green. Positive and negative controls were carried out on slides from the same block. For TUNEL staining, 10 fields were chosen from each group and the percent of TUNEL-positive cells were calculated according to this relation: \% TUNEL-positive neurons $=($ TUNEL-positive neurons (brown)/TUNEL-positive neurons (brown) + normal neurons $($ green$)) \times 100$.

\section{Measurement of pro-inflammatory cytokines}

Hippocampal samples were homogenized in 10 wet weight volumes of TBS, $\mathrm{pH}$ 8.0, containing a cocktail of protease inhibitors $(20 \mathrm{mg} / \mathrm{mL}$ each of pepstatin A, aprotinin, phosphoramidon, and leupeptin, $0.5 \mathrm{mM}$ PMSF, and $1 \mathrm{mM}$ EGTA). Samples were sonicated briefly $(10 \mathrm{~W}, 2 \times 5 \mathrm{~s})$ and centrifuged at $100,000 \times \mathrm{g}$ for $20 \mathrm{~min}$ at $4^{\circ} \mathrm{C}$. The soluble fraction (supernatant) was used for IL- $1 \beta$ and TNF- $\alpha$ ELISAs (R\&D Systems, USA).

\section{Real time RT-PCR analysis}

Expressions of genes were further confirmed by real time PCR. Total RNA from hippocampus tissues were extracted using TriZol reagent (Invitrogen). Reverse transcription was performed with an ExScript RT Reagent Kit (Takara Bio Inc., China). Real-time PCR analysis was undertaken using SYBR Premix Ex Taq (Takara Bio Inc., China). The primers sequences for IL-1 $\beta$ were 5'-GCT GTG GCA GCT ACC TAT GTC TTG-3' (sense) and $5^{\prime}$-AGG TCG TCA TCA TCC CAC GAG-3' (antisense). The primer sequences for TNF- $\alpha$ were $5^{\prime}$ GTG ATC GGT CCC AAC AAG GA-3' (sense) and 5'CTC CCA CCC TAC TTT GCT TGT G-3' (antisense). The primer sequences for $\beta$-actin were $5^{\prime}$-TGA CAG G TG CAG AAG GAG A-3' (sense) and $5^{\prime}$-TAG AGC CAC CAA TCC ACA CA-3' (antisense). The real-time PCR conditions were as follows: initial denaturation at $95^{\circ} \mathrm{C}$ for $10 \mathrm{~s}$ followed by 39 cycles of $95^{\circ} \mathrm{C}$ for $5 \mathrm{~s}$ and $60^{\circ} \mathrm{C}$ for $20 \mathrm{~s}$. The expression levels of the genes were quantified by comparison with a standard curve and normalized relative to levels of $\beta$-actin.

\section{Western blot analysis}

Expression of $\mathrm{A} \beta_{1-40}$, phospho-p38 MAPK, phospho-p65 NF- $\mathrm{kB}$, and phospho-JNK was analyzed by western blot. Thirty $\mu \mathrm{g}$ protein of each sample was heated at $100^{\circ} \mathrm{C}$ for 5 min with a loading buffer containing $0.125 \mathrm{M}$ Tris- $\mathrm{HCl}$ (pH 6.8), 20\% glycerol, 4\% SDS, $10 \%$ mercaptoethanol, and $0.002 \%$ bromophenol blue. It was then separated by sodium dodecyl sulfate-polyacrylamide gel electrophoresis (SDS-PAGE) using 10\% acrylamide gels. The proteins were transferred onto PVDF membranes (pore size, $0.45 \mu \mathrm{m}$ ). Blotting membranes were incubated with $3 \%$ bovine serum albumin (BSA) in tris buffered saline with tween (TBST) $(10 \mathrm{mmol} / \mathrm{L}$ Tris $(\mathrm{pH} 7.5)$, $150 \mathrm{mmol} / \mathrm{L} \mathrm{NaCl}, 0.05 \%$ Tween-20) and probed with corresponding primary antibodies (anti- $\mathrm{A} \beta_{1-40}$, antiphospho-p65 NF-kB, anti-phospho-p38 MAPK, and anti-phospho-JNK, CST, USA) at $4^{\circ} \mathrm{C}$ overnight. After incubation with horseradish peroxidase-coupled secondary antibodies for $2 \mathrm{~h}$ at room temperature, bands were quantitated by densitometry (UVP Upland, CA).

\section{Statistical analysis}

All values were expressed as the mean \pm standard error of the mean (SEM). For the behavioral experiments, the escape latency during the training tests was determined by two-way repeated factor analysis of variance (ANOVA) with Student-Newman-Keuls tests. All other assessments were analyzed using a one-way ANOVA followed by Student-Newman-Keul's or Dunnett's post-hoc analysis. In all cases, $P<0.05$ was considered significant.

\section{Results}

\section{NaHS prevented $A \beta$-induced impairment of spatial learning}

To investigate whether the pre-treatment with NaHS led to functional improvement, we employed the Morris water maze task to examine hippocampus-involved learning and memory. All animals were able to swim normally and find the hidden platform during the training trials. After being trained twice per day for two consecutive sessions, sham and sham $+\mathrm{NaHS}$ rats were able to reach the hidden platform in a shorter time during the training (Figure 1A). However, the learning and memory abilities of $A \beta_{1-40}$-injected rats were significantly impaired compared with the sham group $(P<0.01)$ (Figure 1A). A significant decrease in escape latency was observed in the $\mathrm{NaHS}+\mathrm{A} \beta_{1-40}$ group compared with the $\mathrm{A} \beta_{1-40}$-injected group $(P<0.01)$ (Figure $1 \mathrm{~A}$ ). There was no significant difference in average swim speed among the groups (Figure 1B). These results clearly indicate that $\mathrm{NaHS}$ treatment significantly ameliorated severe deficiencies in spatial cognitive performance induced by $A \beta_{1-40}$.

In the probe trial of the Morris water maze test, $A \beta_{1-40}$ had a significant effect on the time and distance in target quadrant compared with the sham group $(P<0.01)$. Compared with the $\mathrm{A} \beta_{1-40}$-injected group, $\mathrm{NaHS}+\mathrm{A} \beta_{1-40}$ 


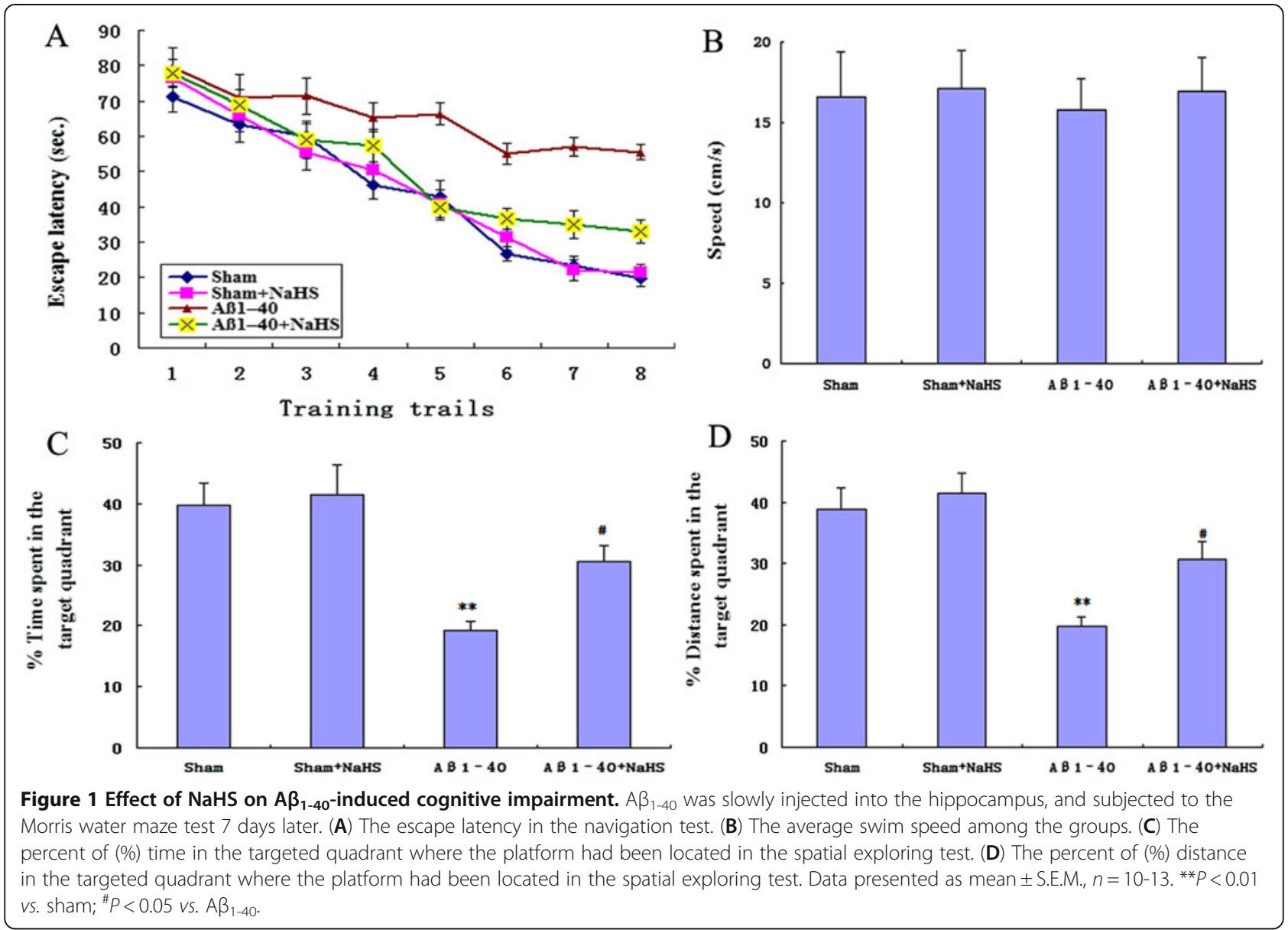

rats displayed more time and distance swimming in the target quadrant $(P<0.05)$ (Figure $1 C, D)$.

\section{NaHS suppressed $A \beta_{1-40}$-induced apoptosis in}

\section{$A \beta_{1-40}$-injection rat model}

To confirm the protective effect of NaHS on $A \beta_{1-40^{-}}$ induced apoptosis, sections through the hippocampus were also examined for the presence of fragmented DNA via TUNEL assay. Microscopic inspection of the hippocampal sections from sham and sham + NaHS rats revealed morphologically normal neurons with no TUNEL reaction. After the injection of $A \beta_{1-40}$, a significant number of TUNEL-positive pyramidal neurons with different degrees of DNA fragmentation were detected in the CA1 subfield of the hippocampus $(P<0.01$ vs. sham). Treatment with NaHS significantly reduced the number of TUNEL-positive neurons $\left(P<0.01 v s . A \beta_{1-40}\right)$ (Figure 2A-E).

NaHS lowered protein levels of $A \beta_{1-40}$ in the hippocampus of rats

Progressive accumulation of $A \beta$ peptides are a major factor in the development of AD pathogenesis [19].
Immunoblot analysis was used to assess the effect of $\mathrm{NaHS}$ on levels of $A \beta_{1-40}$ in area CA1. Infusion of $A \beta$ peptides in normal rats resulted in a marked $(P<0.01)$ accumulation of $A \beta_{1-40}$ levels. NaHS treatment significantly decreased levels of $A \beta_{1-40}$, in $\mathrm{NaHS}+\mathrm{A} \beta_{1-40}$ rats by approximately $31 \%$, compared to those in $A \beta$ rats (A $\beta: 1.75 \pm 0.19 ; \quad \mathrm{NaHS}+\mathrm{A} \beta_{1-40}: 1.21 \pm 0.07, n=5$ rats/ group) (Figure 3A, B).

\section{NaHS decreased $A \beta$-induced astrocytic and microglial response}

Intrahippocampal injection of $\mathrm{A} \beta$ oligomers has been shown to have extended neuroinflammatory responses displaying a significant increase in astrocytic and microglial response that is associated with age and amyloid deposition $[20,21]$. To evaluate the effect of NaHS on the glial response, we performed GFAP (astrocytic) and OX42 (microglial) staining in the hippocampus. GFAP immunostaining demonstrated that injection of $A \beta_{1-40}$ caused reactive gliosis as demonstrated by upregulation of GFAP expression and the presence of hypertrophic astrocytes in the hippocampus $(P<0.01)$ (Figures 4A-E and $4 \mathrm{a}-\mathrm{d})$. In the $\mathrm{NaHS}+\mathrm{A} \beta_{1-40}$ group the number of 


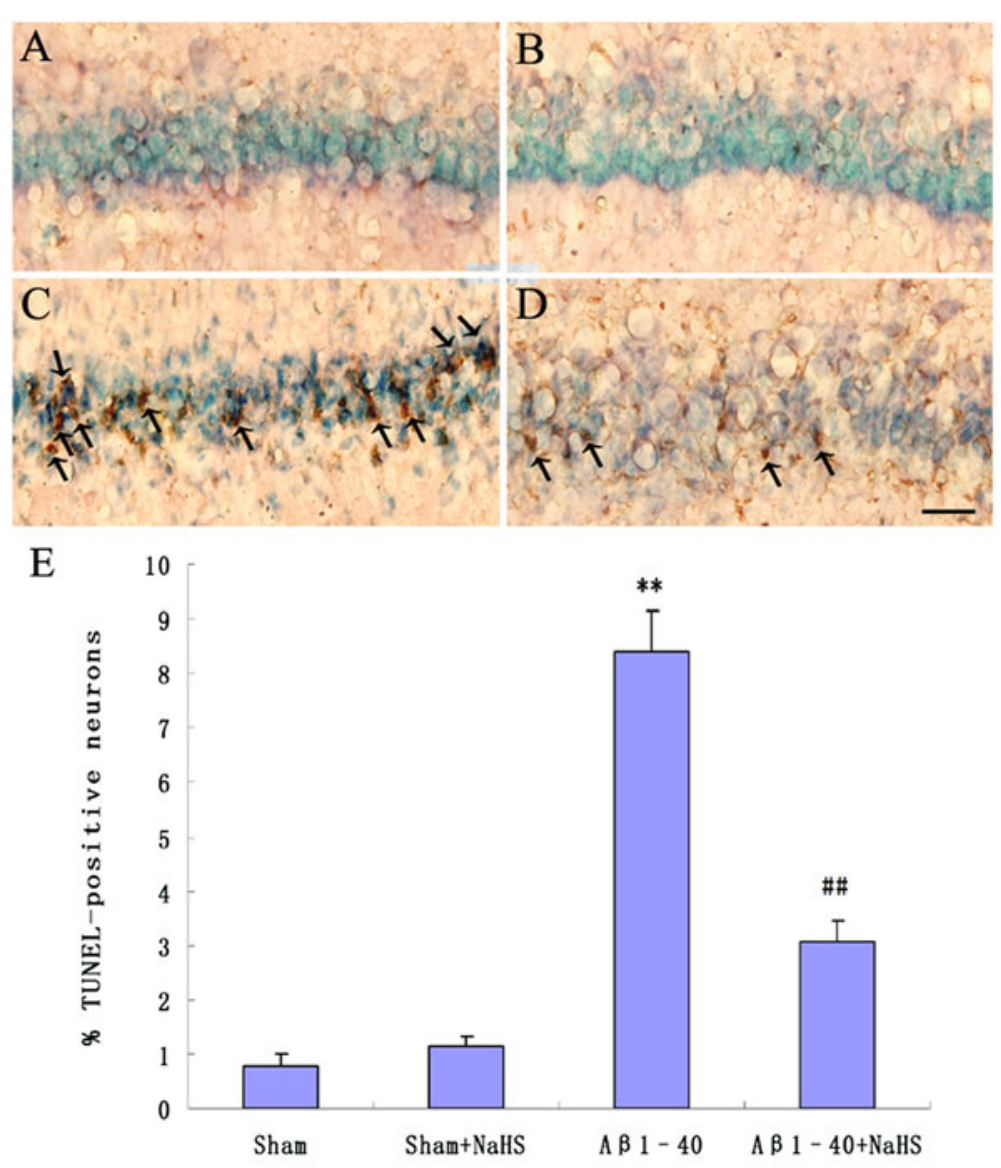

Figure 2 Effects of NaHS on DNA fragmentation in the hippocampus of rats injected with $\mathbf{A} \boldsymbol{\beta}_{1-40}$. (A, B) No TUNEL-reactive cell was detected in the hippocampus from sham and sham + NaHS rats. (C) The significant number of degenerating pyramidal neurons, labeled with the TUNEL technique was observed in the CA1 subfield of the hippocampus. (D) The number of TUNEL-positive neurons significantly decreased in the hippocampus from $A \beta_{1-40}$-injected rats receiving NaHS. Scale bar: $40 \mu \mathrm{m}$. Arrows point to degenerating pyramidal neurons with their nuclei stained with TUNEL technique. (E) Quantitative analysis of \% TUNEL-positive neurons. Data are given as mean \pm S.E.M... ${ }^{*} P<0.01$ vs. sham; ${ }^{\# \#} P<0.01$ vs. $A \beta_{1-40}$.

GFAP-immunoreactive astrocytes was significantly reduced compared to the $\mathrm{A} \beta_{1-40}$-injected group $(P<0.05)$ (Figures $4 \mathrm{~A}-\mathrm{E}$ and $4 \mathrm{a}-\mathrm{d})$. A similar effect was exerted in the $\mathrm{NaHS}+\mathrm{A} \beta_{1-40}$ group where the intensity of OX42-positive microglia was significantly reduced compared to the $A \beta_{1-40}$-injected group (Figure $4 \mathrm{~F}-\mathrm{J}$ ).

\section{NaHS attenuated $A \beta$-induced increases in the levels of} cytokine production and mRNA in the hippocampus

We next addressed whether NaHS was able to ameliorate a generalized pro-inflammatory response from glia. The pro-inflammatory cytokines response was tested by measuring levels of IL-1 $\beta$ and TNF- $\alpha$ in hippocampal brain homogenates. $A \beta_{1-40}$ injection significantly increased the levels of IL- $1 \beta$ and TNF- $\alpha$, and NaHS was able to significantly reduce this response, although levels did not return to that of control (Figure 5A, B).

The effects of NaHS on the mRNA of IL-1 $\beta$ and TNF$\alpha$ were investigated by real-time RT-PCR. Compared with the sham group, injection of $A \beta_{1-40}$ in the hippocampus highly increased the mRNA of IL-1 $\beta$ and TNF$\alpha$, which were approximately 4.7-fold and 2.4-fold, respectively $(P<0.01$, Figure $5 \mathrm{C}, \mathrm{D})$. However, compared to the $\mathrm{A} \beta_{1-40}$ group, treatment with $\mathrm{NaHS}$ significantly decreased the mRNA expressions of these selected genes $(P<0.01$, Figure 5C, D).

\section{NaHS decreased the activation of phospho-p38 MAPK and phospho-p65 NFKB, but not phospho-JNK in the hippocampus}

To further explore the molecular mechanisms underlying the inhibitory effect of $\mathrm{NaHS}$ on the expressions of IL-1 $\beta$ and TNF- $\alpha$, the expressions of phospho-p38 MAPK, phospho-p65 NFKB, and phospho-JNK were determined by western blot analysis. $\mathrm{A} \beta_{1-40}$ injection into the hippocampus significantly enhanced the p38 MAPK, p65 NF-kB, and JNK phosphorylation $(P<0.01$, Figure 6A, B). However, treatment with NaHS caused a 


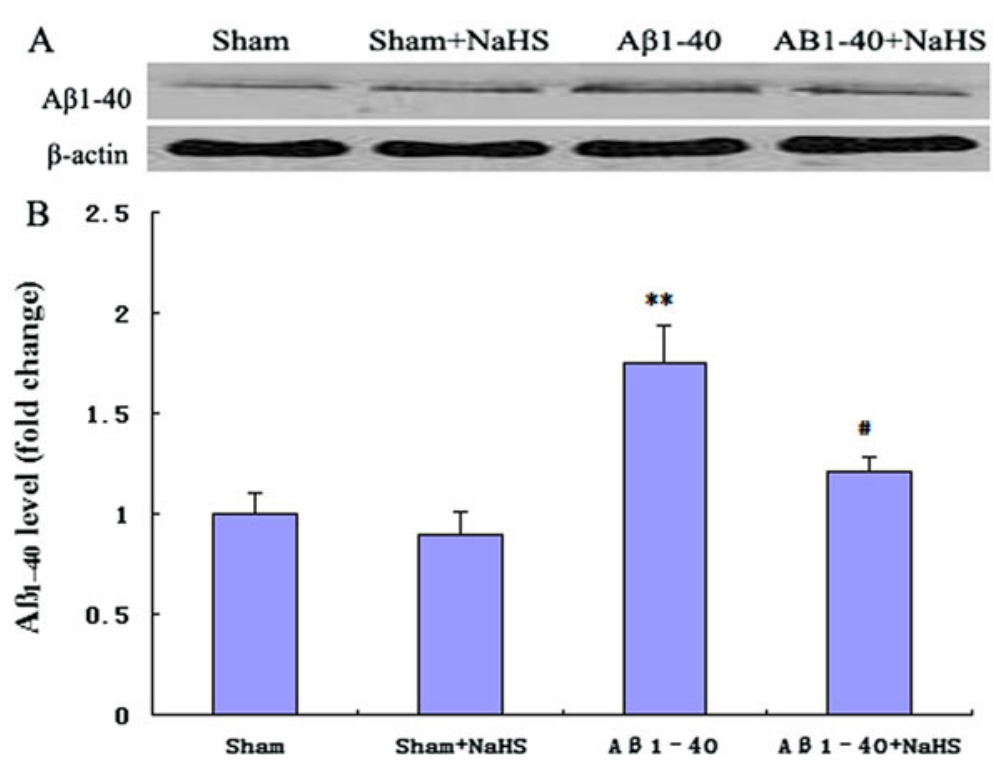

Figure 3 NaHS pre-treatment reduces $\mathbf{A} \boldsymbol{\beta}_{1-40}$ levels. $A \beta_{1-40}$ rats were treated with $\mathrm{NaHS}$ ( $5 \mathrm{mg} / \mathrm{kg}$ i.p. once daily). (A) Western blot of $A \beta_{1-40}$ protein contents. In hippocampal area $C A 1$ the basal levels of $A \beta_{1-40}$ peptides decreased significantly after NaHS treatment. (B) The relative optical density was normalized to $\beta$-Actin. Results are expressed as mean \pm S.E.M. with five rats in each group. ${ }^{* *} P<0.01$ vs. sham; ${ }^{\#} P<0.05$ vs. $A \beta_{1-40}$.
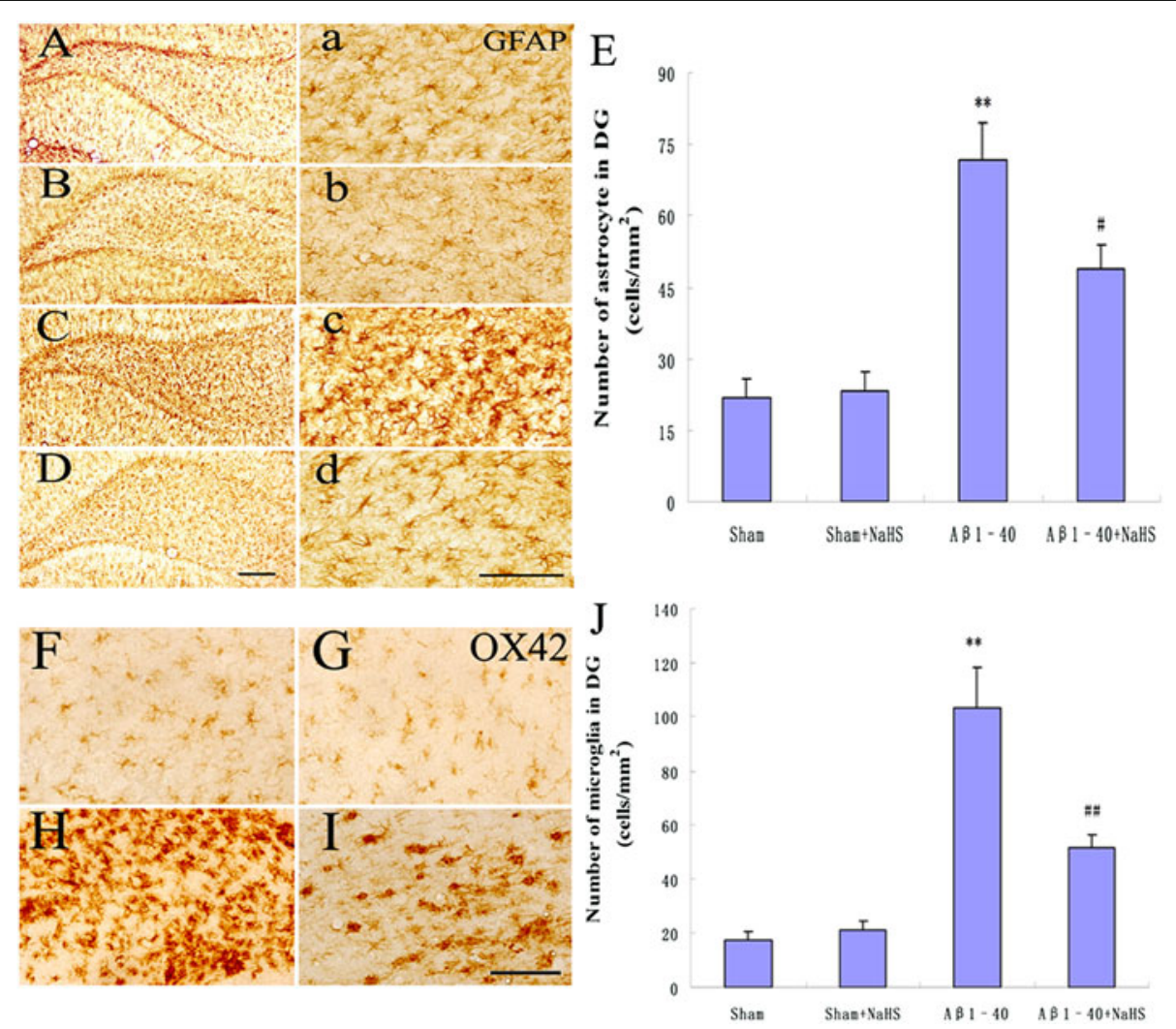

Figure 4 Effect of NaHS on $A \beta_{1-40}$-induced the activation of glia in the DG region of rat hippocampus. (A-E, a-d) The distribution and number of GFAP-immunoreactive astrocytes in sham, sham + NaHS, A $\beta_{1-40}$, and NaHS + A $\beta_{1-40}$ rats. Scale bar, $500 \mu m(\mathbf{A}-\mathbf{D})$ and $50 \mu \mathrm{m}(\mathbf{a}-\mathbf{d})$. (F-J) Representative photographs and number of OX-42-immunopositive cells in sham, sham $+\mathrm{NaHS}, A \beta_{1-40}$, and NaHS $+A \beta_{1-40}$ rats. Scale bar: $250 \mu$ m. Six tissue sections per rat were used for the analysis $(n=8-10)$. Data are presented as the mean \pm S.E.M. ${ }^{* *} P<0.01$ vs. sham; ${ }^{\# \#} P<0.01,{ }^{\# P} P<0.05$ vs. A $\beta_{1-40}$. 

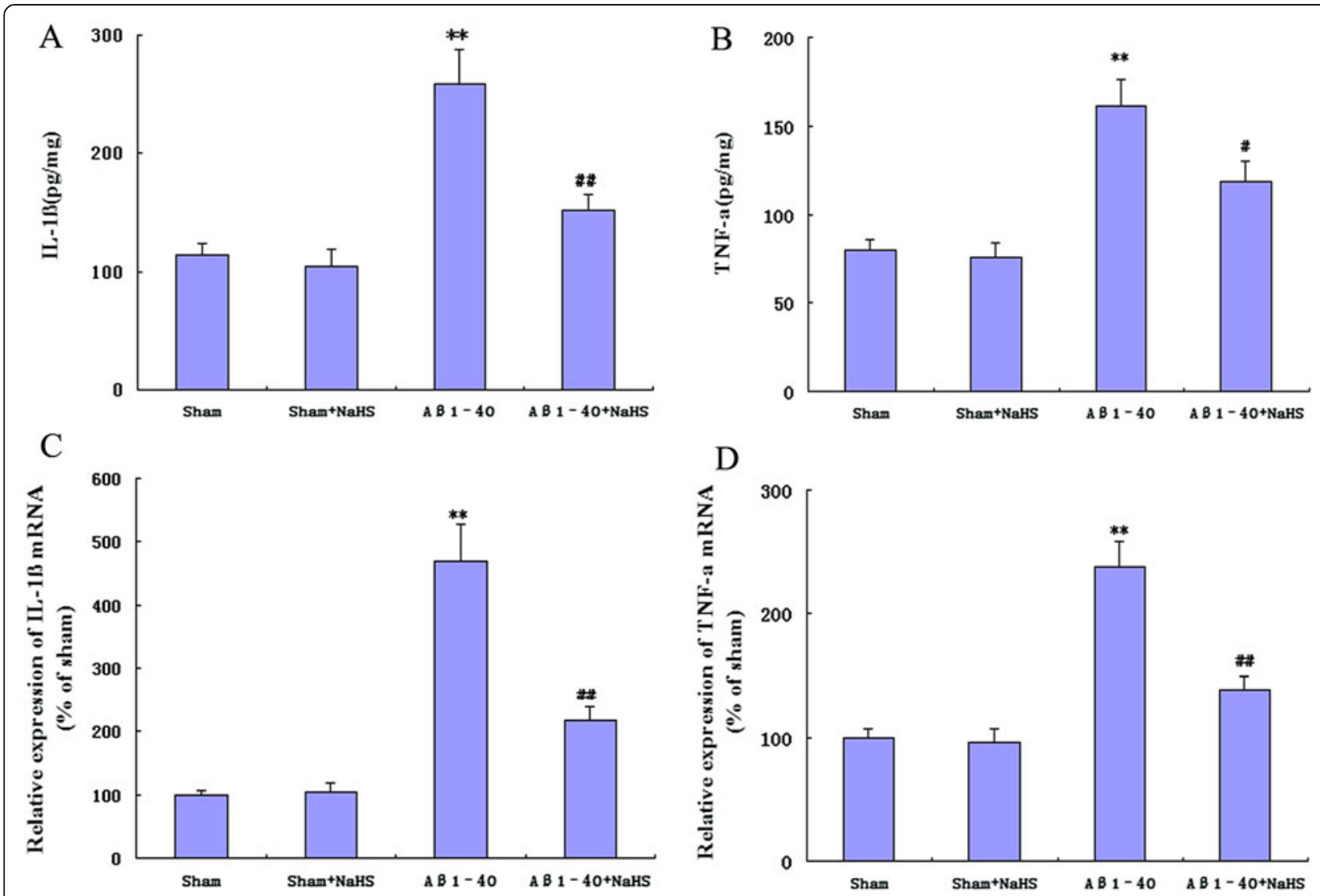

Figure 5 Effect of NaHS on the IL-1 $\beta$, TNF- $\alpha$ production, and mRNA expressions. IL-1 $\beta$ and TNF-a levels in the hippocampus were measured via ELISA. The expressions of IL-1 $\beta$ and TNF-a mRNA in the hippocampus were detected by real time RT-PCR. A $\beta_{1-40}$ injection into the hippocampus significantly increased the IL-1 $\beta$, TNF-a production, and mRNA expressions. Treatments with NaHS significantly decreased the levels and mRNA over-expressions of IL-1 $\beta$ and TNF-a. (A) The level of IL-1 $\beta$. (B) The level of TNF-a. (C) The expressions of IL-1 $\beta$ mRNA. (D) The expressions of TNF-a mRNA. Data are mean \pm S.E.M., $n=4$. ${ }^{* *} P<0.01$ vs. sham; ${ }^{\# \#} P<0.01,{ }^{\#} P<0.05$ vs. A $\beta_{1-40}$.

significant decrease in the phosphorylation of $\mathrm{p} 38$ MAPK and p65 NF-kB but not JNK $(P<0.05$, Figures $6 \mathrm{C}, \mathrm{D})$. Our results show that NaHS treatment suppressed $A \beta_{1-40}$-induced activation of $\mathrm{p} 38$ MAPK and p65 NF- $\mathrm{kB}$ but not JNK, which may contribute to the inhibition of NaHS on the $A \beta_{1-40}$-induced IL- $1 \beta$ and TNF$\alpha$ production.

\section{Discussion}

The deposition of $A \beta$ in brain areas involved in cognitive functions is assumed to initiate a pathological cascade that results in synaptic dysfunction, synaptic loss, and neuronal death [22]. It has been proposed that $A \beta_{1-40}$ aggregates play an important role in the pathogenesis of AD [23]. Numerous reports have showed that the injection of $A \beta_{1-40}$ into rat hippocampus provides an effective model to mimic some of the pathologic and behavioral changes of $\mathrm{AD}$ [24-26]. In our study, we demonstrated that $A \beta_{1-40}$ injection could induce memory deficits and NaHS treatment could also effectively ameliorate $A \beta$ induced impairment of spatial learning.
Memory impairment in $\mathrm{A} \beta$-injected rats was associated with a significant reduction in apoptosis. Apoptosis has been consistently implicated in A $\beta$-induced neuronal damage in vitro, in animal models of $\mathrm{AD}$, and also postmortem studies of AD brain [27-29]. The mechanisms underlying $A \beta$-mediated neurotoxicity still remain to be elucidated, but mounting evidence suggests the involvement of $A \beta$ induced neuroinflammatory in the disease process with $A D$. Studies have shown that $A \beta$ induces the production of neuroinflammatory molecules, which may contribute to the pathogenesis of numerous neurodegenerative diseases [30-32]. However, lots of studies have also demonstrated that anti-inflammatory compounds could exhibit neuroprotective effects in damaged brain cells [33-35]. Central administration of $\mathrm{NaHS}$ prevented $\mathrm{A} \beta_{1-40}$-evoked apoptosis. Decrease in TUNEL-positive neurons may stem from its general suppression of the neuroinflammatory context in the $A \beta_{1-40}$-inflicted hippocampus, thus attenuating the inflammatory cell death.

Evidence suggests that inflammatory reaction induced by $A \beta$ in the $A D$ involves astrogliosis, microgliosis, 

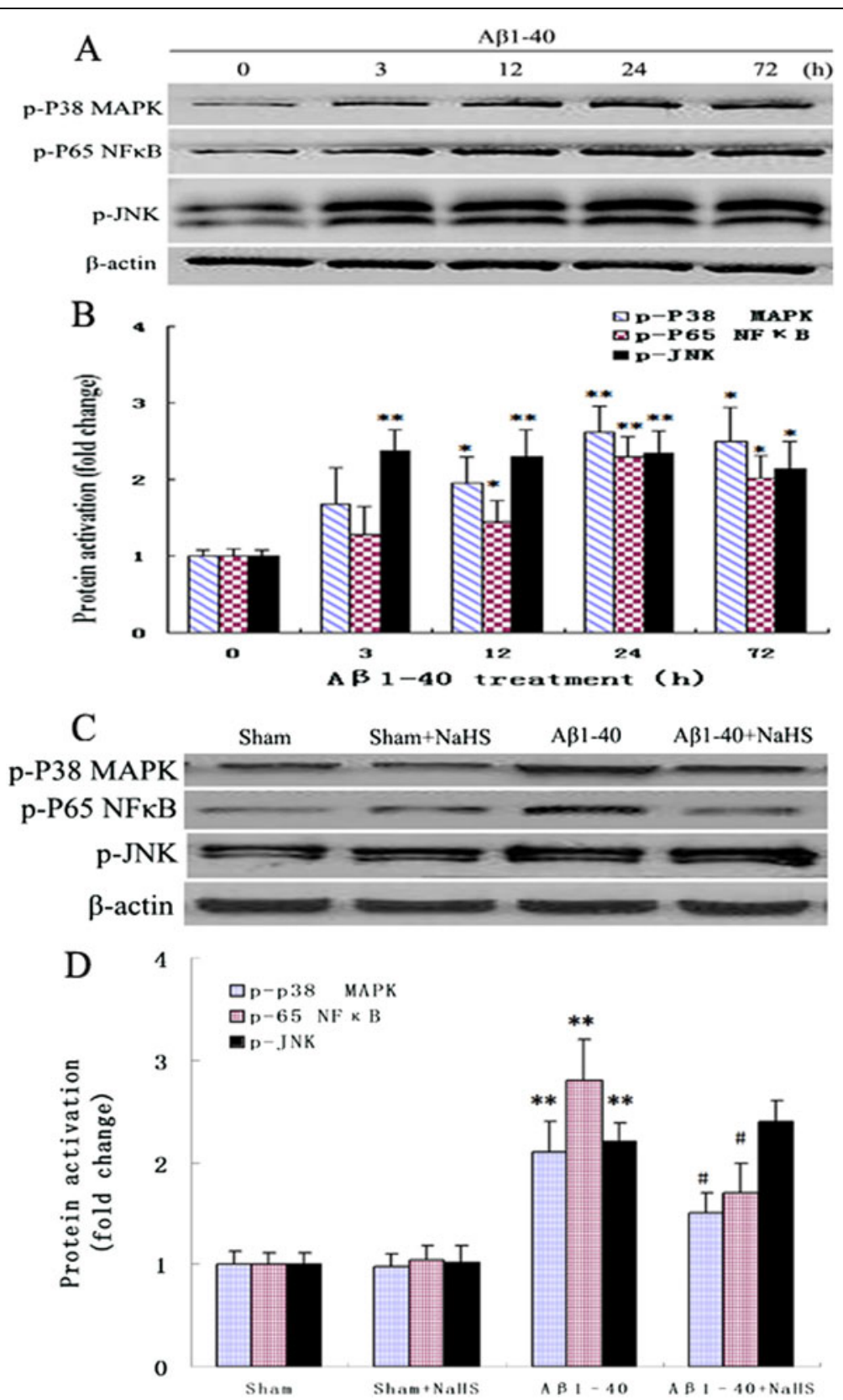

Figure 6 Western blotting analysis of the relative protein contents. (A, C) Western blot of various protein contents for phospho-p38 MAPK, phospho-p65 NFkB, and phospho-JNK. (B, D) The relative optical density was normalized to $\beta$-Actin. Data are mean \pm S.E.M., $n=4$. ${ }^{* *} P<0.01$ ${ }^{*} P<0.05$ vs. sham(control); ${ }^{\#} P<0.05$ vs. $A \beta_{1-40}$.

cytokine elevation, and changes in acute phase proteins $[22,36]$. Activated astrocytes and microglia can secrete inflammatory cytokines and mediators that promote the formation of $A \beta$ and NFTs through numerous signal transduction pathways [37]. In the brains of AD rats, the production of IL-1 $\beta$ and TNF- $\alpha$ play an important role in augmenting inflammatory reaction and formation of $A \beta$ [38]. Several reports have provided evidence demonstrating a role for IL-1 $\beta$ in the etiology of AD based largely on the finding that IL-1 $\beta$ expression in different brain areas in $\mathrm{AD}$ and also in the cerebrospinal fluid of $\mathrm{AD}$ patients $[39,40]$. Consistently, the injection of $\mathrm{A} \beta$ increases the hippocampal mRNA expression of both TNF- $\alpha$ and inducible nitric oxide synthase (iNOS), of which the former was stronger, and the knock-out of TNF- $\alpha$ (TNF- $\alpha(-/-)$ ) in mouse prevented the increase of iNOS mRNA in the hippocampus and the impairment of recognition memory in mice induced by $A \beta$ [41]. It has been proposed that elevated levels of proinflammatory cytokines, including TNF- $\alpha$, may inhibit 
phagocytosis of $\mathrm{A} \beta$ in $\mathrm{AD}$ brains thereby hindering efficient plaque removal by resident microglia [42]. In our studies, we demonstrated that the hippocampus of the $A \beta_{1-40}$ group had the activation of astrogliosis and microgliosis as well as the strong increase of IL-1 $\beta$ and TNF- $\alpha$ compared with the sham group, indicating that the two inflammatory cytokines were involved in the inflammatory response in $\mathrm{AD}$ rats.

Our results demonstrated that NaHS treatment decreased $A \beta_{1-40}$-induced astrocytic and microglial response as well as inflammatory cytokines expression. A previous study showed that $\mathrm{H}_{2} \mathrm{~S}$ was synthesized in brain primarily by the enzyme CBS, and that astrocytes were the most active producers of $\mathrm{H}_{2} \mathrm{~S}$, with much smaller quantities being generated by microglia [43]. $\mathrm{H}_{2} \mathrm{~S}$ production is suppressed by inflammatory stimulation of microglia and astrocytes, and this suppression reduces the natural anti-inflammatory effect of $\mathrm{H}_{2} \mathrm{~S}$ [14]. $\mathrm{H}_{2} \mathrm{~S}$ has been reported to exhibit marked anti-inflammatory activity in LPS-induced lung, liver, and kidney tissue inflammatory damage in the mouse [44]. Another result reveals that $\mathrm{H}_{2} \mathrm{~S}$ releasing NSAIDS $\mathrm{S}$-aspirin and Sdiclofenac attenuates the neuroinflammation induced by activation of glia [45]. Administration of NaHS significantly attenuates LPS-induced cognitive impairment through reducing the overproduction of proinflammatory mediators, and accompanied by an increase of $\mathrm{H}_{2} \mathrm{~S}$ levels [46]. However, there is no direct evidence that $\mathrm{H}_{2} \mathrm{~S}$ attenuates inflammatory initiated neuronal death, which is closely associated with the pathogenesis of several neurodegenerative diseases including AD.

To further understand the molecular mechanisms of the effects of NaHS on the expressions of IL- $1 \beta$ and TNF- $\alpha$, the expressions of phospho-p38 MAPK, phospho-p65 NF-kB, and phospho-JNK were analyzed by western blot. Numerous studies demonstrate that injection of $A \beta$ into the hippocampus, cortex, and nucleus basalis induces the activity of p38 MAPK, NF- $\mathrm{kB}$, and JNK in rat [47-50]. p38 MAPK activation has been implicated in the pathogenesis of $\mathrm{AD}$, and significant increase of MAPK kinase 6 (MKK6), one of the upstream activators of p38 MAPK, is observed in hippocampal and cortical regions of individuals with $\mathrm{AD}$ compared with age-matched controls [51]. Chronic exposure of human microglia to $A \beta_{1-42}$ led to enhanced p38 MAPK expression [36]. NF- $\mathrm{kB}$ is known to upregulate the expressions of cytokines, chemokines, adhesion molecules, acute phase proteins, and inducible effector enzymes. NF- $\mathrm{kB}$ is composed of several protein subunits, among which p65 has been extensively studied. In AD brains, p65 NF- $\mathrm{kB}$ immunoreactivity is greater in neurons and astrocytes surrounding amyloid plaques $[52,53]$. Additionally, it has been reported that $A \beta$ stimulation leads to p $65 \mathrm{NF}-\mathrm{kB}$ activation in cultured neurons and glia [54]. One study has revealed that increased hippocampal IL-1ßconcentration, paralleled by increased JNK activation in AD brain [51]. The activation of JNK has been described in cultured neurons after $A \beta$ exposure, and their inhibition attenuates $A \beta$ toxicity $[49,55]$. Corroborating these findings, the present results show that increased hippocampal concentration of inflammatory cytokines stimulated by $\mathrm{A} \beta$ is accompanied by phosphorylation of p38 MAPK, p65 NF-kB, and JNK.

Our data also suggest that the effects of $\mathrm{H}_{2} \mathrm{~S}$ against the released levels of pro-inflammatory cytokines such as IL-1 $\beta$ and TNF- $\alpha$ may include the capability of this gas to reduce the levels of phospho-p38 MAPK and phospho-p65 NF- $\mathrm{kB}$ but not phospho-JNK. This is consistent with reports that S-diclofenac decreases the activation of $\mathrm{NFKB}$ and other pro-inflammatory cytokines in rat plasma and liver homogenates [44] and that NaHS attenuates LPS-induced inflammation by inhibition of p38 MAPK and p65 NF- $\mathrm{kB}$ in rodent microglia and rat $[12,46]$.

\section{Conclusions}

In conclusion, our results clearly demonstrated that: (1) a single injection of $A \beta_{1-40}$ into the hippocampus produced cognitive impairment in rats, apoptosis, and the glial response, with concomitant production of IL-1 $\beta$ and TNF- $\alpha$, and these effects occurred via activation of p38 MAPK, p65 NF- $\mathrm{kB}$, and phospho-JNK in rat's hippocampus; and (2) pretreatment with NaHS significantly attenuated $\mathrm{A} \beta_{1-40}$-induced cognitive deficits, apoptosis, and the glial response, with concomitant inhibitions of IL-1 $\beta$ and TNF- $\alpha$ production, as well as repressed $A \beta_{1-40}$-induced activation of $\mathrm{p} 38$ MAPK and p65 NF-кB.

\section{Competing interests}

The authors declare that they have no competing interests.

\section{Authors' contributions}

AX designed the study, conducted molecular assays and the data analysis. $D L$ participated in the design of the study. JIANL performed the TUNEL assay. WJ carried out the RT-PCR. MZ performed the immunohistochemistry. $\mathrm{LH}$ performed the Morris water maze. JIL participated in the ELISA and performed the statistical analysis. AX, DL, WJ, MZ, LH, and JIANL drafted and/ or criticized the manuscript. All authors read and approved the final manuscript.

\section{Acknowledgements}

This research was co-financed by grants from Natural Science Foundation of China (No. 30900728), Medical Scientific Research Foundation of Guangdong Province (No. A2010228), Science Foundation of Education Bureau of Guangzhou City (No. 10A156).

\section{Author details}

'Department of Anatomy, Guangzhou Medical University, Guangzhou, China. ${ }^{2}$ Department of Physiology, Guangzhou Medical University, Guangzhou, China. ${ }^{3}$ Department of Urology, Minimally Invasive Surgery Center, Guangdong Provincial Key Laboratory of Urology, The First Affiliated Hospital of Guangzhou Medical University, Guangzhou, China. ${ }^{4}$ Department of Neurobiology, Southern Medical University, Guangzhou, China. 
Received: 8 May 2012 Accepted: 4 August 2012

Published: 17 August 2012

\section{References}

1. Mildner A, Schlevogt B, Kierdorf K, Böttcher C, Erny D, Kummer MP, Quinn M, Brück W, Bechmann I, Heneka MT, Priller J, Prinz M: Distinct and nonredundant roles of microglia and myeloid subsets in mouse models of Alzheimer's disease. J Neurosci 2011, 31:11159-11171.

2. Eikelenboom P, van Exel E, Hoozemans JJ, Veerhuis R, Rozemuller AJ, van Gool WA: Neuroinflammation-an early event in both the history and pathogenesis of Alzheimer's disease. Neurodegener Dis 2010, 7:38-41.

3. Seabrook TJ, Jiang L, Maier M, Lemere CA: Minocycline affects microglia activation, Abeta deposition, and behavior in APP-tg mice. Glia 2006, 53:776-782

4. Weldon DT, Rogers SD, Ghilard JR, Finke MP, Cleary JP, O'Hare E, Esler WP, Maggio JE, Mantyh PW: Fibrillar beta-amyloid induces microglial phagocytosis, expression of inducible nitric oxide synthase, and loss of a select population of neurons in the rat CNS in vivo. J Neurosci 1998, 18:2161-2173.

5. Potter PE: Investigational medications for treatment of patients with Alzheimer disease. J Am Osteopath Assoc 2010, Suppl 8:27-36.

6. Kamoun P: Endogenous production of hydrogen sulfide in mammals. Amino Acids 2004, 26:243-254.

7. Shibuya N, Tanaka M, Yoshida M, Ogasawara Y, Togawa T, Ishii K, Kimura H: 3-Mercaptopyruvate sulfurtransferase produces hydrogen sulfide and bound sulfane sulfur in the brain. Antioxid Redox Signal 2009, 11:703-714.

8. Kimura $Y$, Kimura $H$ : Hydrogen sulfide protects neurons from oxidative stress. FASEB J 2004, 18:1165-1167.

9. Yin $W L, H e ~ J Q, ~ H u ~ B$, Jiang ZS, Tang XQ: Hydrogen sulfide inhibits MPP (+)-induced apoptosis in PC12 cells. Life Sci 2009, 85:269-275.

10. Lee SW, Hu YS, Hu LF, Lu Q, Dawe GS, Moore PK, Wong PT, Bian JS: Hydrogen sulphide regulates calcium homeostasis in microglial cells. Glia 2006, 54:116-124.

11. Nagai $Y$, Tsugane M, Oka J, Kimura H: Hydrogen sulfide induces calcium waves in astrocytes. FASEB J 2004, 18:557-559.

12. Hu LF, Wong PT, Moore PK, Bian JS: Hydrogen sulfide attenuates lipopolysaccharide induced inflammation by inhibition of p38 mitogenactivated protein kinase in microglia. J Neurochem 2007, 100:1121-1128.

13. Morrison LD, Smith DD, Kish SJ: Brain S-adenosylmethionine levels are severely decreased in Alzheimer's disease. J Neurochem 1996, 67:1328-1331.

14. Lee M, Schwab C, Yu S, McGeer E, McGeer PL: Astrocytes produce the antiinflammatory and neuroprotective agent hydrogen sulfide. Neurobio/ Aging 2009, 30:1523-1534.

15. Gong QH, Wang Q, Pan LL, Liu XH, Huang H, Zhu YZ: Hydrogen sulfide attenuates lipopolysaccharide-induced cognitive impairment: A proinflammatory pathway in rats. Pharmacol Biochem BE 2010, 96:52-58.

16. Qu K, Chen CP, Halliwell B, Moore PK, Wong PT: Hydrogen sulfide is a mediator of cerebral ischemic damage. Stroke 2006, 37:889-893.

17. Huang HJ, Liang KC, Chen CP, Chen CM, Hsieh-Li HM: Intrahippocampal administration of $A$ beta(1-40) impairs spatial learning and memory in hyperglycemic mice. Neurobiol Learn Mem 2007, 87:483-494

18. Morris R: Developments of a water-maze procedure for studying spatial learning in the rat. J Neurosci Methods 1984, 11:47-60.

19. Srivareerat M, Tran TT, Salim S, Aleisa AM, Alkadhi KA: Chronic nicotine restores normal $A \beta$ levels and prevents short-term memory and E-LTP impairment in $A \beta$ rat model of Alzheimer's disease. Neurobiol Aging 2011 , 32:834-844.

20. Bagheri M, Roghani M, Joghataei MT, Mohseni S: Genistein inhibits aggregation of exogenous amyloid-beta ${ }_{1-40}$ and alleviates astrogliosis in the hippocampus of rats. Brain Res 2012, 1429:145-154.

21. Miguel-Hidalgo JJ, Cacabelos R: Beta-amyloid(1-40)-induced neurodegeneration in the rat hippocampal neurons of the CA1 subfield. Acta Neuropathol 1998, 95:455-465.

22. Walsh DM, Selkoe DJ: Deciphering the molecular basis of memory failure in Alzheimer's disease. Neuron 2004, 44:181-193.

23. Hashimoto T, Adams KW, Fan Z, McLean PJ, Hyman BT: Characterization of oligomer formation of amyloid-beta peptide using a split-luciferase complementation assay. J Biol Chem 2011, 286:27081-27091.

24. Shin RW, Ogino K, Kondo A, Saido TC, Trojanowski JQ, Kitamoto T, Tateishi J: Amyloid beta-protein (Abeta) 1-40 but not Abeta1-42 contributes to the experimental formation of Alzheimer disease amyloid fibrils in rat brain. J Neurosci 1997, 17:8187-8193.

25. Yamaguchi Y, Miyashita H, Tsunekawa H, Mouri A, Kim HC, Saito K, Matsuno T, Kawashima S, Nabeshima T: Effects of a novel cognitive enhancer, spiro [imidazo-[1,2-a] pyridine -3,2- indan]-2(3H)-one (ZSET1446), on learning impairments induced by amyloid-beta1-40 in the rat. J Pharmacol Exp Ther 2006, 317:1079-1087.

26. Zou K, Kim D, Kakio A, Byun K, Gong JS, Kim J, Kim M, Sawamura N Nishimoto S, Matsuzaki K, Lee B, Yanagisawa K, Michikawa M: Amyloid betaprotein (Abeta) 1-40 protects neurons from damage induced by Abeta142 in culture and in rat brain. J Neurochem 2003, 87:609-619.

27. Yu Y, Zhou L, Sun M, Zhou T, Zhong K, Wang H, Liu Y, Liu X, Xiao R, Ge J, Tu P, Fan DS, Lan $Y$, Hui $C$, Chui D: Xylocoside $G$ reduces amyloid- $\beta$ induced neurotoxicity by inhibiting NF-KB signaling pathway in neuronal cells. J Alzheimers Dis 2012, 30:263-275.

28. Hwang DY, Chae KR, Kang TS, Hwang JH, Lim CH, Kang HK, Goo JS, Lee MR, Lim HJ, Min SH, Cho JY, Hong JT, Song CW, Paik SG, Cho JS, Kim YK: Alterations in behavior, amyloid beta-42, caspase-3, and Cox-2 in mutant PS2 transgenic mouse model of Alzheimer's disease. FASEB J 2002, 6:805-813

29. Dragunow M, Faull RL, Lawlor P, Beilharz EJ, Singleton K, Walker EB, Mee E: In situ evidence for DNA fragmentation in Huntington's disease striatum and Alzheimer's disease temporal lobes. Neuroreport 1995, 6:1053-1057.

30. Tweedie D, Ferguson RA, Fishman K, Frankola KA, Van Praag H, Holloway HW, Luo W, Li Y, Caracciolo L, Russo I, Barlati S, Ray B, Lahiri DK, Bosetti F, Greig NH, Rosi S: Tumor necrosis factor-a synthesis inhibitor 3,6'dithiothalidomide attenuates markers of inflammation. Alzheimer pathology and behavioral deficits in animal models of neuroinflammation and Alzheimer's disease. J Neuroinflammation 2012, 9:106

31. Liu S, Liu Y, Hao W, Wolf L, Kiliaan AJ, Penke B, Rübe CE, Walter J, Heneka MT, Hartmann T, Menger MD, Fassbender K: TLR2 is a primary receptor for Alzheimer's amyloid $\beta$ peptide to trigger neuroinflammatory activation. J Immunol 2012, 188:1098-1107.

32. Maeda J, Ji B, Irie T, Tomiyama T, Maruyama M, Okauchi T, Staufenbiel M, Iwata N, Ono M, Saido TC, Suzuki K, Mori H, Higuchi M, Suhara T: Longitudinal, quantitative assessment of amyloid, neuroinflammation, and anti-amyloid treatment in a living mouse model of Alzheimer's disease enabled by positron emission tomography. J Neurosci 2007, 27:10957-10968.

33. Zhu LH, Bi W, Qi RB, Wang HD, Wang ZG, Zeng Q, Zhao YR, Lu DX: Luteolin reduces primary hippocampal neurons death induced by neuroinflammation. Neurol Res 2011, 33:927-934.

34. Lee JY, Cho E, Ko YE, Kim I, Lee KJ, Kwon SU, Kang DW, Kim JS: Ibudilast, a phosphodiesterase inhibitor with anti-inflammatory activity, protects against ischemic brain injury in rats. Brain Res 2012, 1431:97-106.

35. Liu $T$, Jin $H$, Sun $Q R, X u J H, H u H T$ : The neuroprotective effects of tanshinone IIA on $\beta$-amyloid-induced toxicity in rat cortical neurons. Neuropharmacology 2010, 59:595-604.

36. Franciosi S, Ryu JK, Choi HB, Radov L, Kim SU, McLarnon JG: Broadspectrum effects of 4-aminopyridine to modulate amyloid beta1-42induced cell signaling and functional responses in human microglia. $J$ Neurosci 2006, 26:11652-11664.

37. Peila R, Launer LJ: Inflammation and dementia: epidemiologic evidence. Acta Neurol Scand Suppl 2006, 185:102-106.

38. Morales I, Farías G, Maccioni RB: Neuroimmunomodulation in the pathogenesis of Alzheimer's disease. Neuroimmunomodulation 2010, 17:202-204.

39. Angelopoulos P, Agouridaki H, Vaiopoulos H, Siskou E, Doutsou K, Costa V, Baloyiannis SI: Cytokines in Alzheimer's disease and vascular dementia. Int J Neurosci 2008, 118:1659-1672

40. Forlenza OV, Diniz BS, Talib LL, Mendonça VA, Ojopi EB, Gattaz WF, Teixeira AL: Increased serum IL-1beta level in Alzheimer's disease and mild cognitive impairment. Dement Geriatr Cogn Disord 2009, 28:507-512.

41. Alkam T, Nitta A, Mizoguchi H, Saito K, Seshima M, Itoh A, Yamada K, Nabeshima T: Restraining tumor necrosis factor-alpha by thalidomide prevents the amyloid beta-induced impairment of recognition memory in mice. Behav Brain Res 2008, 189:100-106.

42. Koenigsknecht-Talboo J, Landreth GE: Microglial phagocytosis induced by fibrillar beta-amyloid and IgGs are differentially regulated by proinflammatory cytokines. J Neurosci 2005, 25:8240-8249. 
43. Abe $\mathrm{K}$, Kimura $\mathrm{H}$ : The possible role of hydrogen sulfide as an endogenous neuromodulator. J Neurosci 1996, 16:1066-1071.

44. Li L, Bhatia M, Zhu YZ, Zhu YC, Ramnath RD, Wang ZJ, Anuar FB, Whiteman M, Salto-Tellez M, Moore PK: Hydrogen sulfide is a novel mediator of lipopolysaccharide-induced inflammation in the mouse. FASEB J 2005, 19:1196-1198.

45. Lee M, Sparatore A, Del Soldato P, McGeer E, McGeer PL: Hydrogen sulfidereleasing NSAIDs attenuate neuroinflammation induced by microglial and astrocytic activation. Glia 2010, 58:103-113.

46. Gong QH, Wang Q, Pan LL, Liu XH, Huang H, Zhu YZ: Hydrogen sulfide attenuates lipopolysaccharide-induced cognitive impairment: a proinflammatory pathway in rats. Pharmacol Biochem Behav 2010, 96:52-58.

47. Giovannini MG, Scal C, Prosperi C, Bellucci A, Vannucchi MG, Rosi S, Pepeu G, Casamenti F: Beta-amyloid-induced inflammation and cholinergic hypofunction in the rat brain in vivo: involvement of the p38MAPK pathway. Neurobiol Dis 2002, 11:257-274.

48. Ji C, Aisa HA, Yang N, Li Q, Wang T, Zhang L, Qu K, Zhu HB, Zuo PP. Gossypium herbaceam extracts inhibited NF-kappaB activation to attenuate spatial memory impairment and hippocampal neurodegeneration induced by amyloid-beta in rats. J Alzheimers Dis 2008, 14:271-283.

49. Minogue AM, Lynch AM, Loane DJ, Herron CE, Lynch MA: Modulation of amyloid-beta-induced and age-associated changes in rat hippocampus by eicosapentaenoic acid. J Neurochem 2007, 103:914-926.

50. Wang C, Li J, Liu Q, Yang R, Zhang JH, Cao YP, Sun XJ: Hydrogen-rich saline reduces oxidative stress and inflammation by inhibit of JNK and NF-KB activation in a rat model of amyloid-beta-induced Alzheimer's disease. Neurosci Lett 2011, 491:127-132.

51. Zhu X, Rottkamp CA, Hartzler A, Sun Z, Takeda A, Boux H, Shimohama S, Perry G, Smith MA: Activation of MKK6, an upstream activator of p38, in Alzheimer's disease. J Neurochem 2001, 79:311-318.

52. Kaltschmidt B, Uherek M, Volk B, Baeuerle PA, Kaltschmidt C: Transcription factor NF-kappaB is activated in primary neurons by amyloid beta peptides and in neurons surrounding early plaques from patients with Alzheimer disease. Proc Natl Acad Sci U S A 1997, 94:2642-2647.

53. Kitamura Y, Shimohama S, Ota T, Matsuoka Y, Nomura Y, Taniguchi T: Alteration of transcription factors NF-kappaB and STAT1 in Alzheimer's disease brains. Neurosci Lett 1997, 237:17-20.

54. Chen J, Zhou Y, Mueller-Steiner S, Chen LF, Kwon H, Yi S, Mucke L, Gan L: SIRT1 protects against microglia-dependent amyloid-beta toxicity through inhibiting NF-kappaB signaling. J Biol Chem 2005, 280:40364-40374.

55. Ebenezer PJ, Weidner AM, LeVine H 3rd, Markesbery WR, Murphy MP, Zhang L, Dasuri K, Fernandez-Kim SO, Bruce-Keller AJ, Gavilán E, Keller JN: Neuron specific toxicity of oligomeric amyloid- $\beta$ : role for JUN-kinase and oxidative stress. J Alzheimers Dis 2010, 22:839-848.

doi:10.1186/1742-2094-9-202

Cite this article as: Xuan et al:: Hydrogen sulfide attenuates spatial memory impairment and hippocampal neuroinflammation in betaamyloid rat model of Alzheimer's disease. Journal of Neuroinflammation 2012 9:202

\section{Submit your next manuscript to BioMed Central and take full advantage of:}

- Convenient online submission

- Thorough peer review

- No space constraints or color figure charges

- Immediate publication on acceptance

- Inclusion in PubMed, CAS, Scopus and Google Scholar

- Research which is freely available for redistribution 